\title{
HUBUNGAN ANTARA PERAN PENYULUH PERTANIAN DENGAN PARTISIPASI PETANI DALAM USAHATANI PADI HITAM DI KELURAHAN CIKALANG KECAMATAN TAWANG KOTA TASIKMALAYA
}

\author{
CORRELATION BETWEEN AGRICULTURAL EXTENSION RULE AND FARMER \\ PARTICIPATION REGARDING BLACK RICE CROPS IN CIKALANG, TAWANG, \\ MUNICIPALITY TASIKMALAYA
}

\author{
Irsyad Padjari, Ristina Siti Sundari", Dona Setia Umbara \\ Universitas Perjuangan, Jl. PETA No. 177 Tasikmalaya 46115 \\ *E-mail: ristina.sitisundari@yahoo.com \\ (Diterima 18-06-2021; Disetujui 07-07-2021)
}

\begin{abstract}
ABSTRAK
Pangan merupakan kebutuhan dasar manusia yang paling utama dan pemenuhannya merupakan bagian dari hak asasi manusia. Setelah ketahanan pangan terjaga maka masyarakat mengarahkan orientasinya untuk dapat menjaga pangan yang dimakan memiliki nilai gizi yang dibutuhkan dan gaya hidup sehat. Padi hitam dapat memenuhi keamanan pangan dan gaya hidup sehat. Penelitian dilakukan untuk mengetahui hubungan peran penyuluh dan partisipasi petani dalam usahatani padi hitam. Metode yang digunakan adalah studi kasus dengan jumlah sampel mengikuti rumus Yamane, Isaac, dan michel. Data yang dikumpulkan berasal dari data primer melalui wawancara langsung dengan petani dan data sekunder melalui kajian pustaka, internet, lembaga atau instansi terkait. Analisis data menggunakan Rank Spearman. Hasil penelitian menunjukkan bahwa terdapat hubungan signifikan yang kuat dan searah antara peran penyuluh pertanian dengan partisipasi petani dalam usahatani padi hitam. Semakin tinggi peran penyuluh pertanian, maka semakin tinggi partisipasi petani dalam berusahatani padi hitam. Konsumen padi hitan tidak sebanyak konsumen padi putih. Padi hitam dikonsumsi oleh orang yang bergaya hidup sehat.
\end{abstract}

Kata kunci: Padi hitam; partisipasi; peran penyuluh; usahatani

\section{ABSTRACT}

Food is the basic need of human beings, and to fulfill it is our right to secure food. Then lead to safe the food as better nutrition needs and lifestyle. Balck rice can meet both food safety and a healthy lifestyle. The research was conducted to investigate the correlation between agricultural extension role and farmer participation in black rice crops. The method used case study by the amount of sample by Yamane, Isaac, and Michel Formula accordingly. The collected data was primary and secondary data by direct questionnaire and literature study from internet and related institutions. Data analysis used Rank Spearman Test. The result showed a significant correlation and one direction deal with agricultural extension rule and farmer participation in black rice crops. The more agricultural extension rule, the more farmer participation in black rice crops. Black rice consumer was not as much as white rice. Black rice consumer refers to consume deal with healthy lifestyle.

Keywords: Black rice, participation, extension role, Crops

\section{PENDAHULUAN}

Padi hitam merupakan salah satu padi lokal yang mempunyai keunggulan tersendiri dibandingkan padi lainnya, antara lain mempunyai pigmen alami, yaitu mengandung antosianin yang 
bermanfaat untuk kesehatan kadar antosianin dalam padi hitam sebesar 30$1167 \mathrm{mg} / 100 \mathrm{~g}$ hasil ekstraksi, dan 322 $\mathrm{mg} / 100 \mathrm{~g}$ pada padi utuh khususnya pada penderita diabetes (Nurhidayah \& Isnaeni 2019). Kecamatan Tawang merupakan salah satu wilayah yang memproduksi padi hitam di Kota Tasikmalaya.

Tabel 1. Luas Panen dan Jumlah Produksi Padi Hitam di Kecamatan Tawang Tahun2015 - 2019

\begin{tabular}{|c|c|c|c|c|c|c|c|c|}
\hline \multirow{3}{*}{ No. } & \multirow{3}{*}{$\begin{array}{l}\text { Tahun } \\
\text { Tanam }\end{array}$} & \multicolumn{2}{|c|}{$\begin{array}{c}\text { Luas Tanam Hitam } \\
\text { (Ha) }\end{array}$} & \multicolumn{2}{|c|}{$\begin{array}{c}\text { Jumlah Produksi } \\
\text { (Ton) }\end{array}$} & \multirow{3}{*}{ Jumlah } & \multirow{3}{*}{$\begin{array}{c}\text { Rata- } \\
\text { rata per } \\
\text { musim }\end{array}$} & \multirow{3}{*}{$\begin{array}{c}\text { Persentase } \\
\quad(\%)\end{array}$} \\
\hline & & \multicolumn{4}{|c|}{ Musim Tanam } & & & \\
\hline & & 1 & 2 & 1 & 2 & & & \\
\hline 1 & 2015 & 1,3 & 1,3 & 5,2 & 5,46 & 10,6 & 5,33 & \\
\hline 2 & 2016 & 2,5 & 3,8 & 10,7 & 15,96 & 26,7 & 13,355 & $151 \%$ \\
\hline 3 & 2017 & 0,25 & 0,75 & 1,02 & 2,85 & 6,6 & 3,325 & $75 \%$ \\
\hline 4 & 2018 & 1,38 & 2,92 & 6,4 & 13,87 & 20,3 & 10,178 & $207 \%$ \\
\hline \multirow[t]{2}{*}{5} & 2019 & 3,2 & 4,92 & 14,5 & 22,632 & 37,1 & 18,596 & $82 \%$ \\
\hline & Total & 8,63 & 13. 69 & 57,07 & 60,77 & 120,84 & 50,724 & \\
\hline Rata & a per tahur & 2,11 & 2,28 & 10,01 & 10,13 & 19,63 & 9,824 & \\
\hline
\end{tabular}

Sumber: P4S Trimukti 2015-2020

Berdasarkan Tabel 1, produksi padi hitam yang ada di Kecamatan Tawang tepatnya di Kelurahan Cikalang terjadi fluktuasi dari tahun ke tahun. Pada tahun 2015 jumlah produksi padi hitam mencapai 10,6 ton, artinya terjadi peningkatan dengan persentase 151\% pada tahun 2016 dengan jumlah 26.7 ton. Namun, terjadi penurunan pada tahun 2017 dengan persentase $75 \%$ menjadi 6.6 ton, tetapi pada tahun 2018 terjadi peningkatan lagi menjadi 207\% dengan jumlah 20,3 Ton, pada tahun 2019 terjadi peningkatan yang sangat pesat dengan persentase $82 \%$ menjadi 37,1 ton.

Keberhasilan peningkatan produksi dan luas panen padi hitam ini tidak lepas dari berbagai faktor, salah satunya peran penyuluh pertanian serta partisipasi masyarakat atau kelompok tani.
Partispasi petani melalui pengikutsertaan petani dapat menjadi cara yang efisien untuk mencapai tujuan usahatani padi hitam yang telah dirumuskan oleh pemerintah dan pejabat penyuluhan. Penyuluh diharapkan juga mampu berperan sebagai fasilitator untuk mengembangkan usaha agribisnis yang dilakukan oleh petani, buruh tani dan rumah tangga tani di perdesaan, sekaligus dapat memfasilitasi penumbuhan Lembaga Keuangan Mikro Agribisnis (LKM-A). Keberhasilan penyuluh sebagai fasilitator dalam pengembangan usaha agribisnis dan penumbuhan poktan juga ditentukan oleh koordinasi dan kerjasama yang baik dan saling mendukung dengan seluruh pemangku kepentingan yang terlibat dalam 
usahatani padi hitam, di Kota Tasikmalaya khususnya.

Yusak (2021) menyatakan bahwa peranan penyuluhan pertanian menjadi belum optimal dapat disebabkan oleh kurangnya tingkat partisipasi petani terhadap penyuluh pertanian. Hal ini mungkin sebagai akibat mutu pelayanan penyuluhan pertanian yang masih rendah. Selain sistem pendanaan, juga mungkin masih belum sistematis, dengan demikian dapat menyebabkan kinerja penyuluh pertanian menjadi rendah dalam menjalankan tugas dan fungsinya. Penyuluh pertanian diharapkan dapat menciptakan dirinya sebagai mitra dan fasilitator petani dengan melakukan peranan yang sesuai antara lain sebagai: penyedia jasa pendidikan (educator), motivator, konsultan (pembimbing), dan pendamping petani.

Mardikanto (1993) dan (Yusuf 2019) menjelaskan partisipasi menggambarkan keikutsertaan seseorang atau sekelompok orang dalam suatu kegiatan. Terdapat empat macam kegiatan yang menunjukkan partisipasi masyarakat di dalam kegiatan pembangunan, diantaranya partisipasi dalam pengambilan keputusan, pelaksanaan program, pemantauan dan evaluasi, serta dalam pemanfaatan hasil pembangunan. Seperti halnya padi hitam.

Partisipasi dibagi menjadi dua macam, yaitu partisipasi aktif dan partispasi pasif. Partisipasi aktif dicerminkan pada keikutsertaan dalam suatu kegiatan baik berupa tenaga, waktu, uang, materi dan pikiran dari masyarakat. Sedangkan partisipasi pasif adalah keikutsertaan tanpa memberikan sesuatu baik tenaga, pikiran dan materi.

Proses penyuluhan pertanian diharapkan dapat meningkatkan produktivitas lahan dan produksi padi padi hitam, jika didukung dengan implementasi di lapangan dengan memberikan perhatian kepada semua pihak, khususnya petani. Kemudian yang disampaikan penyuluh dapat diimplementasikan oleh petani agar dapat menciptakan peningkatan produktivitas baik lahan maupun hasil panen padi hitam.

Sehubungan dengan hal tersebut maka perlu penelitian untuk mengetahui hubungan yang terjadi antara peran penyuluh pertanian dan partisipasi petani dalam usahatani padi hitam di Kelurahan Cikalang Kecamatan Tawang Kota Tasikmalaya. 


\section{METODE PENELITIAN}

Metode dasar penelitian yang digunakan adalah studi kasus pada Kelompok tani Muara Hurip dengan pertimbangan karakteristik kelompok tani yang lebih aktif dan lebih maju dalam pengembangan usahatani padi hitam. Penelitian ini merupakan penelitian dengan pendekatan deskriptif agar dapat membuat gambaran yang sistematis, faktual dan tepat ataupun akurat mengenai fakta, sifat serta hubungan antar fenomena yang diobservasi (Sugiyono 2014). Jumlah populasi sudah diketahui yaitu sebanyak 34 petani padi hitam maka penarikan sampel menurut (Sugiyono 2019) dapat menggunakan rumus Yamane, Isaac, dan Michel yaitu:

$$
\mathrm{n}=\frac{N}{1+N(e)^{2}}
$$

Keterangan:

$\mathrm{n}$ = Jumlah sampel yang diperlukan

$\mathrm{N}=$ Jumlah populasi

e $=$ Tingkat kesalahan (sampling eror)

$$
\mathrm{n}=\frac{N}{1+N(e)^{2}}=\frac{34}{1+34(0,05)^{2}}=\frac{34}{1,085}=31,33
$$

Berdasarkan perhitungan jumlah sampel yang akan menjadi sampel dalam penelitian ini dibulatkan ke atas menjadi 32 orang, dari total keseluruhan populasi petani padi beras hitam di Kelurahan Cikalang Kecamatan Tawang. Ini dilakukan untuk memudahkan penelitian yang akan dilakukan serta untuk mendapatkan hasil pengujian data yang lebih baik. Teknik yang diambil menggunakan probability sampling dengan simple random sampling, dimana semua populasi petani padi beras hitam yang ada di Kelurahan Cikalang memiliki peluang yang sama untuk menjadi sampel tanpa memperhitungkan siapapun.

Peran penyuluh pertanian termasuk aspek dinamis dari kedudukan seorang penyuluh yang sedang melaksanakan hak dan kewajibannya (Purnaningsih \& Satria 2015).

Penelitian ini terdapat dua variabel, yaitu peran penyuluh pertanian $(\mathrm{X})$ dan partisipasi (Y). Kemudian dilakukan penskoran dari kriteria peran penyuluh pertanian dan partisipasi dimana skor 5 diberikan nilai untuk sangat baik, skor 4 untuk nilai baik, skor 3 untuk nilai cukup baik, skor 2 untuk nilai buruk, dan skor 1 untuk nilai sangat buruk.

Operasionalisasi variabel peran penyuluh pertanian $(\mathrm{X})$ terdiri atas peran sebagai motivator, innovator, organosator, fasilitator dan dinamisator. Sedangkan variabel partisipasi petani dalam usahatani padi hitam (Y) sebagai pengambil keputusan, pelaksana, pemantau dan evaluasi. 
Pengujian untuk mengukur hubungan antara peran penyuluh pertanian terhadap partisipasi petani pada usahatani padi hitam di Kelurahan Cikalang Kecamatan Tawang Kota Tasikmalaya menggunakan Uji Korelasi Rank Spearman (Siegel, 1990) dengan prosedur analisis sebagai berikut:

1) Penentuan Hipotesis

$H_{0}: \rho=0 \rightarrow$ Tidak terdapat hubungan antara peranan penyuluh pertanian dengan partisipasi petani dalam usahatani padi hitan di Kelurahan Cikalang Kecamatan Tawang Kota Tasikmalaya.

$H_{1}: \rho \neq 0 \rightarrow$ ada hubungan antara peran penyuluh pertanian dan partisipasi petani dalam usahatani padi hitam di Kelurahan Cikalang Kecamatan Tawang Kota Tasikmalaya.

Menentukan Nilai Korelasi

Bila tidak ada rank kembar atau rank kembar hanya sedikit menggunakan rumus sebagai berikut:

$$
\mathrm{r}_{\mathrm{S}}=1-\frac{6 \sum_{i=1}^{n} d i^{2}}{n^{3}-n}
$$

Bila ada rank kembar maka nilai korelasi menggunakan rumus sebagai berikut :

$$
\mathrm{r}_{\mathrm{s}}=\frac{\sum X^{2}+\sum Y^{2}+\sum d i^{2}}{2 \sqrt{\sum X^{2} \cdot \sum Y^{2}}}
$$

Keterangan:

$\mathrm{Rs}=$ koefisien korelasi

$\mathrm{t}$ = banyak kembaran data

$\mathrm{n}=$ jumlah responden $\mathrm{x}=$ peranan penyuluh pertanian

$\mathrm{y}=$ partisipasi petani dalam usahatani padi hitam

$\mathrm{d}_{\mathrm{i}}=$ selisih dari variabel $\mathrm{X}$ dan $\mathrm{Y}$

Untuk mendapatkan nilai $\sum X^{2}$ dan $\sum Y^{2}$ diperoleh dengan rumus :

$$
\begin{aligned}
& \sum X^{2}=\frac{N^{3}-N}{12}-\sum T_{x} \text { dan } \\
& \sum Y^{2}=\frac{N^{3}-N}{12}-\sum T_{y}
\end{aligned}
$$

Nilai $\mathrm{T}_{\mathrm{x}}$ dan $\mathrm{T}_{\mathrm{y}}$ dirumuskan :

$$
\mathrm{T}_{\mathrm{x}}=\sum \frac{t^{3}-t}{12} \text { dan } \mathrm{T}_{\mathrm{y}}=\sum \frac{t^{3}-t}{12}
$$

Dengan $\mathrm{t}=$ banyak kembaran data.

2) Menguji Nilai Korelasi $\left(T_{r s}\right)$

Untuk mencari $\mathrm{T}_{\mathrm{rs}}$ digunakan rumus:

$$
\mathrm{T}_{\mathrm{rs}}=\mathrm{r}_{\mathrm{s}} \sqrt{\frac{n-2}{1-r_{s}^{2}}}
$$

$t_{\alpha}$ dicari dengan menggunakan tabel, pada derajat bebas $(\mathrm{db})=\mathrm{n}-2$ pada taraf nyata $(\alpha=0,05)$

3) Kaidah Keputusan

Bila $\mathrm{t}_{\mathrm{rs}} \leq t_{\alpha}(\mathrm{n}-2) \rightarrow$ Terima $\mathrm{H}_{0}$ dan Tolak $\mathrm{H}_{1}$

Bila $t_{\mathrm{rs}}>t_{\alpha}(\mathrm{n}-2) \rightarrow$ Terima $\mathrm{H}_{1}$ dan Tolak $\mathrm{H}_{0}$, dimana $\alpha=0,1$

Erat tidakanya hubungan antar variabel dapat diketahui dengan penafsiran koefisien (Sugiyono 2014):
a. $0,00-0,25$, sangat lemah
b. 0,26-0,50, cukup
c. 0,51-0,75, kuat
d. 0,76-0,99 korelasi sangat kuat 
e. 1,00, korelasi sempurna

\section{HASIL DAN PEMBAHASAN}

Hasil penelitian menggunakan uji korelasi Rank Spearman, dapat dilihat pada Tabel 1 yang menunjukkan bahwa peran penyuluhan pertanian memiliki hubungan dengan partisipasi petani dalam usahatani padi hitam di Kelurahan Cikalang Kecamatan Tawang Kota Tasikmalaya. Hasil uji korelasi Rank
Spearman diperoleh nilai signifikansi sebesar 0,523 . Nilai tersebut lebih besar dibandingkan dengan nilai $\alpha=0,01$ maka keputusannya adalah menolak $\mathrm{H}_{0}$ dan menerima $\mathrm{H}_{1}$. Hal ini bararti terdapat hubungan antara peran penyuluh pertanian dengan partisipasi petani dalam usahatani padi hitam di Kelurahan Cikalang Kecamatan Tawang Kota Tasikmalaya.

Tabel 1. Korelasi

\begin{tabular}{lllcc}
\hline & & Peran Penyuluh & Partisipasi Petani \\
\hline Spearman's rho & Peranan Penyuluh & Koefisien Korelasi & 1.000 & $.523^{* *}$ \\
& & Sig. (2-tailed) &. & .002 \\
& $\mathrm{~N}$ & 32 & 32 \\
& \multirow{2}{*}{ Partisipasi Petani } & Koefisien Korelasi & $.523^{* *}$ & 1.000 \\
& & Sig. (2-tailed) & .002 &. \\
& $\mathrm{~N}$ & 32 & 32 \\
\hline
\end{tabular}

**. Correlation is significant at the 0.01 level (2-tailed)

Nilai korelasi Rank Spearman (rs) hubungan antara peran penyuluh pertanian dengan partisipasi petani dalam usahatani padi hitam di Kelurahan Cikalang Kecamatan Tawang Kota Tasikmalaya adalah sebesar 0,523 ; maka penafsiran keeratan hubungan berdasar pendapat dari (Sugiyono 2003) menunjukkan tingkat kekuatan (keeratan) hubungan peran penyuluh pertanian dengat partisipasi petani sebesar 0,523 termasuk kategori hubungan yang kuat. Hubungan kedua variabel bersifat searah, semakin tinggi peran penyuluh pertanian maka semakin tinggi partisipasi petani dalam berusahatani padi hitam. Nilai signifikansi 2 arah 0.002 lebih kecil $(<)$ dari 0.05 atau 0.01 , terdapat hubungan yang signifikan antara peran penyuluh pertanian dengan partisipasi petani. Hasil penelitian ini didukung oleh penelitian (Nopitasari et al. 2017) yang menunjukan terdapat hubungan anatara peran penyuluh pertanian lapangan dengan partisipasi kelompok wanita tani dengan industri pengelolaan pangan lokal dengan taraf kepercayaan 95\% sehingga 
memiliki hubungan yang signifikan dan searah.

Pernyataan lain diungkapkan dalam hasil penelitian penelitian dari (Rangkuti et al. 2018) dengan hasil data menunjukan bahwa kategori dan hasil keseluruhan peran penyuluh dari kelempok tani dalam pengembangan kelompok tani tanaman kopi adalah 11,07 dengan kategori cukup berperan. Selain itu, penelitian dari (Aisyah 2016) menunjukan hasil bahwa peranan penyuluhan pertanian berpengaruh terhadap tingkat penerapan sistem tanam jajar legowo dengan persentase $69 \%$ dengan kategori tinggi. Sedangkan penelitian dari (Padmaswari et al., 2018) menunjukkan hasil bahwa keseluruhan jawaban responden diperoleh pencapaian skor rata-rata 3,94 yang memiliki kategori baik.

Konsumen padi hitan tidak sebanyak konsumen padi putih. Padi hitam dikonsumsi oleh orang yang bergaya hidup sehat.

\section{KESIMPULAN DAN SARAN}

\section{Kesimpulan}

Terdapat hubungan signifikan yang kuat dan searah antara peran penyuluh pertanian dengan partisipasi petani dalam usahatani padi hitam. Semakin tinggi peran penyuluh pertanian maka semakin tinggi partisipasi petani dalam berusahatani padi hitam.

\section{Saran}

Konsumen padi hitam tidak sebanyak konsumen padi putih. Padi hitam dikonsumsi oleh orang yang bergaya hidup sehat. Untuk itu perlu dipromosikan gaya hidup sehat dengan mengonsumsi padi hitam. Selain itu, program yang berkaitan dengan padi hitam sebaiknya juga berfokus pada kesejahteraan para pelaku usaha padi hitam. Di samping itu perlu ada keseimbangan yang proporsional dalam diversifikasi usahatani padi, baik padi hitam, padi putih, padi merah, padi ketan putih dan padi ketan hitam.

\section{DAFTAR PUSTAKA}

Aisyah, S. 2016. "Peranan Penyuluhan Pertanian Terhadap Penerapan Sistem Tanam Jajar Legowo." (peranan penyuluhan).

BPS. 2020. "Statistic Indonesia Statistical Yearbook of Indonesia." Retrieved April 22, 2021 (https://www.bps.go.id/publication/ download.html?nrbvfeve $=$ ZTkwM TFiMzE1NWQ0NWQ3MDgyM2 MxNDFm\&xzmn=aHR0cHM6Ly9 3d3cuYnBzLmdvLmlkL3B1Ymxp Y2F0aW9uLzIwMjAvMDQvMjkv ZTkwMTFiMzE1NWQ0NWQ3M DgyM2MxNDFmL3N0YXRpc3Rp aylpbmRvbmVzaWEtMjAyMC5o dG1s\&twoadfnoarfeauf $=$ MjAyMS0 wNC0). 
Mardikanto, T. 1993. Penyuluh Pembangunan Pertanian.

Surakarta: Sebelas maret University Press.

Nopitasari, E., Suherman, G., dan Gunawan. 2017. "Hubungan Peran Penyuluh Pertanian Lapang Dengan Tingkat Partisipasi Anggota Kelompok Dalam Industri Pengolahan Pangan Lokal." Jurnal Agribisnis Terpadu 10(1):64. doi: 10.33512/jat.v10i1.5056.

Nurhidayah, S, and Isnaeni, S. 2019. "Keberhasilan Persilangan Padi Beras Putih Dan Padi Beras Hitam (Oryza Sativa L.)." Agrosintesa Jurnal Ilmu Budidaya Pertanian 2(2):82-87.

Padmaswari, S., Ni Putu Istri, N, and I. Putra, G.S.A. 2018. "Peranan Penyuluh Pertanian Lapangan (PPL) Sebagai Fasilitator Usahatani Petani Di Subak Empas Buahan Kecamatan Tabanan Kabupaten Tabanan." Jurnal Agribisnis Dan Agrowisata (Journal of Agribusiness and Agritourism) 7(2):277. doi: 10.24843/jaa.2018.v07.i02.p11.

Purnaningsih, N, and Satria, A. 2015. "Peranan Penyuluh Swadaya Dalam Mendukung Intensifikasi Kakao Di Kabupaten Sigi Provinsi Sulawesi Tengah The." Jurnal Penyuluhan 11(2):201-11.

Rangkuti, K, Harahap, M, and Wien R. 2018. "Peran Penyuluh Pertanian Dalam Pengembangan Kelompok Tani Tanaman Kopi Di Desa Jongkok Raya Kec. Bandar Kab, Bener Meriah." JASc (Journal of Agribusiness Sciences) 01(2):2.

Rudiana, A., Herdiansah, D, and Hardiyanto, T. 2017. "Partisipasi Dalam Kegiatan Kelompok Tani (Studi Kasus Pada Kelompoktani Irmas Jaya Di Desa Karyamukti Kecamatan Pataruman Kota
Banjar)." Jurnal Ilmiah Mahasiswa Agroinfo Galuh 2(2):75. doi: 10.25157/jimag.v2i2.61.

Sasongko, DA. 2011. "Penyuluh Pertanian." Retrieved June 12, 2021 (http://eprints.undip.ac.id/52830/3/ Bab_II.pdf).

Siegel, Sidney. 1990. Statistik Nonparametrik Untuk Ilmu-Ilmu Sosial. Jakarta.

Sugiyono. 2003. Metode Penelitian. Bandung: Alfabeta.

Sugiyono. 2014. Metode Penelitian Pendikan Kuantati, Dan R\&D. Bandung: Alfabeta.

Sugiyono. 2019. Metode Penelitian Kuantitatif Kualtatif. Ke-2. Bandung: Alfabeta.

Sundari, Yusra, A.H.A. dan Nurliza. 2015. "Peran Penyuluh Pertanian Dalam Peningkatan Produksi Usahatani Di Kabupaten Pontianak." Jurnal Social Economic of Agriculture 4(1):2631 .

Tanjungsari, K., Haryadi, S.S. dan Endang S. 2017. "Pengaruh Peran Petugas Lapang Terhadap Partisipasi Petani Dalam Pengembangan Model Desa Kakao Di Kabupaten Gunungkidul.” Agro Ekonomi 27(2):121. doi: 10.22146/jae.22877.

Yusak, M, Fauzia, L., Rotinga, A. 2021. "Presepsi Petani Perkebunan Karet Rakyat Terhadap Kinerja Penyuluh Perkebunan." Retrieved April 22, 2021

(https://media.neliti.com/media/pub lications/15093-ID-persepsi-petanipekebun-karet-rakyat-terhadapkinerja-penyuluh-perkebunankasus.pdf).

Yusuf, M. 2019. "Partisipasi Masyarakat Dalam Pembangunan Di GAng Tanjung Kelurahan Sungai Pinang Luar Kota Samarinda." Ilmu Pemerintahan 7(4):1849-60. 